\title{
Asian-Pacific Oscillation signal from a Qomolangma (Mount Everest) ice-core chemical record
}

\author{
Hao XU, Shugui HOU, Hongxi PANG \\ MOE Key Laboratory for Coast and Island Development, School of Geographic and Oceanographic Sciences, \\ Nanjing University, Nanjing, China \\ E-mail: shugui@nju.edu.cn
}

\begin{abstract}
The Asian-Pacific Oscillation (APO) is a climate pattern related to the thermal differences between the Asian continent and the north Pacific. We present a 1000 year record of the major ions in a $108.83 \mathrm{~m}$ ice core from east Rongbuk glacier $\left(2^{\circ} 01^{\prime} \mathrm{N}, 8^{\circ}{ }^{\circ} 8^{\prime} \mathrm{E} ; 6518 \mathrm{~m}\right.$ a.s.l.) on the northeast slope of Qomolangma (Mount Everest), and discuss its relationship with a 993 year time series of the summer APO index that has been reconstructed from Beijing's summer temperature (recorded by a stalagmite) and the Pacific Decadal Oscillation (PDO) index. Empirical orthogonal function (EOF) analysis shows that crustal major ions $\left(\mathrm{Mg}^{2+}, \mathrm{Ca}^{2+}, \mathrm{SO}_{4}{ }^{2-}\right.$ and $\mathrm{NO}_{3}{ }^{-}$) are highly loaded on $\mathrm{EOF1}$, whereas marine major ions $\left(\mathrm{Cl}^{-}\right.$and $\left.\mathrm{Na}^{+}\right)$are highly loaded on EOF2. Higher EOF1 is associated with lower upper-troposphere temperature (UTT) over Mongolia, corresponding to a lower APO index and higher surface pressure. Higher EOF2 is associated with higher UTT over Mongolia, corresponding to a higher APO index and lower surface pressure. The higher burden of major ions and higher summer APO index during the period AD 1000-1323 may be due to drought and warm climate of the major-ion source regions. From AD 1323 to 1900, EOF1 and EOF2 do not show a consistent correlation with summer APO index, indicating the complex mechanisms of ion transport over the southern Tibetan Plateau (TP) during this period. After AD 1900, the summer APO index is correlated negatively with EOF1 and positively with EOF2, indicating that ion transport over the southern TP during this period is influenced significantly by the APO. Our examinations of the PDO index and major-ion record show that higher PDO corresponds to higher EOF1 and lower EOF2. This suggests that the correlation between the recorded major-ion concentration and the APO index originates in the seesaw relationship in temperature between the Asian continent and the north Pacific.
\end{abstract}

KEYWORDS: ice core

\section{INTRODUCTION}

The Tibetan Plateau (TP), known as the third pole, is the highest land on Earth, with an average altitude of $>4000 \mathrm{~m}$. Its many mountain glaciers and ice caps comprise the largest glaciated area outside the polar regions. Ice cores retrieved from their accumulation zone preserve a wealth of high-resolution paleoclimatic and environmental information (Mayewski and others, 1984; Thompson and others, $1989,1997,2000)$ and contribute much to the estimation of past climate changes and their linkage with the Asian monsoon (Wake and others, 1993). Investigations of the major ions in ice cores recovered from this region show the ions' sources and controlling factors (Wake and others, 1993; Kang and others, 2002). Ions transported to the southern TP have two main sources: marine aerosols from the Arabian Sea and the Bay of Bengal, and continental aerosols from central Asia. The ions originating from continental and marine aerosols are named crustal and marine ions, respectively. Several ions $\left(\mathrm{Ca}^{2+}, \mathrm{Mg}^{2+}, \mathrm{SO}_{4}{ }^{2-}\right.$ and $\mathrm{NO}_{3}{ }^{-}$) show higher concentrations outside the monsoon season, accompanied by dust aerosols from the arid regions of central and southern Asia, and are associated with the predominance of continental air masses (Wake and others, 1993; Kang and others, 2002). Marine ions are transported to the southern TP during summer and are associated with the occurrence of the south Asian monsoon (Wake and others, 1993; Shrestha and others, 2002). Therefore the range of ions can record the atmospheric circulations over the southern TP (Kang and others, 2002; Shrestha and others, 2002; Kaspari and others, 2007).

East Rongbuk (ER) glacier is located on the southern margin of the TP (Fig. 1) at an altitude of 6000-6600 m, and lies at the boundary of the south Asian monsoon and westerlies (Kang and others, 2002; Kaspari and others, 2007). High accumulation rate $\left(\sim 50 \mathrm{~cm}\right.$ w.e. $\left.\mathrm{a}^{-1}\right)$ and low temperature in the ice (borehole temperatures from $-8.4^{\circ} \mathrm{C}$ to $-9.85^{\circ} \mathrm{C}$ ) at the site enable the preservation of the climatic and environmental record (Hou and others, 2003; Xu and others, 2010). Previous investigations of chemical records in the ER ice core have verified that the summer Mongolia high strengthens the control of the continental air mass and weakens the south Asian monsoon over the southern TP (Kang and others, 2002; Kaspari and others, 2007), and the winter Mongolia high strengthens the westerlies over the southern TP (Kang and others, 2002).

The Asian-Pacific Oscillation (APO), first proposed by Zhao and others (2007), refers to a summer zonal teleconnection pattern over the extratropical Asian-Pacific region that exhibits a seesaw relationship in the middle-/ upper-tropospheric (500-200 hPa) mean temperature between Asia and the north Pacific (Zhao and others, 2007). When the troposphere cools in the mid-latitudes of the Asian continent, it warms in the mid-latitudes of the central and eastern north Pacific, as well as in North America and the north Atlantic Ocean, and vice versa (Zhao and others, 2007, 2010). This thermal pattern is associated with the 


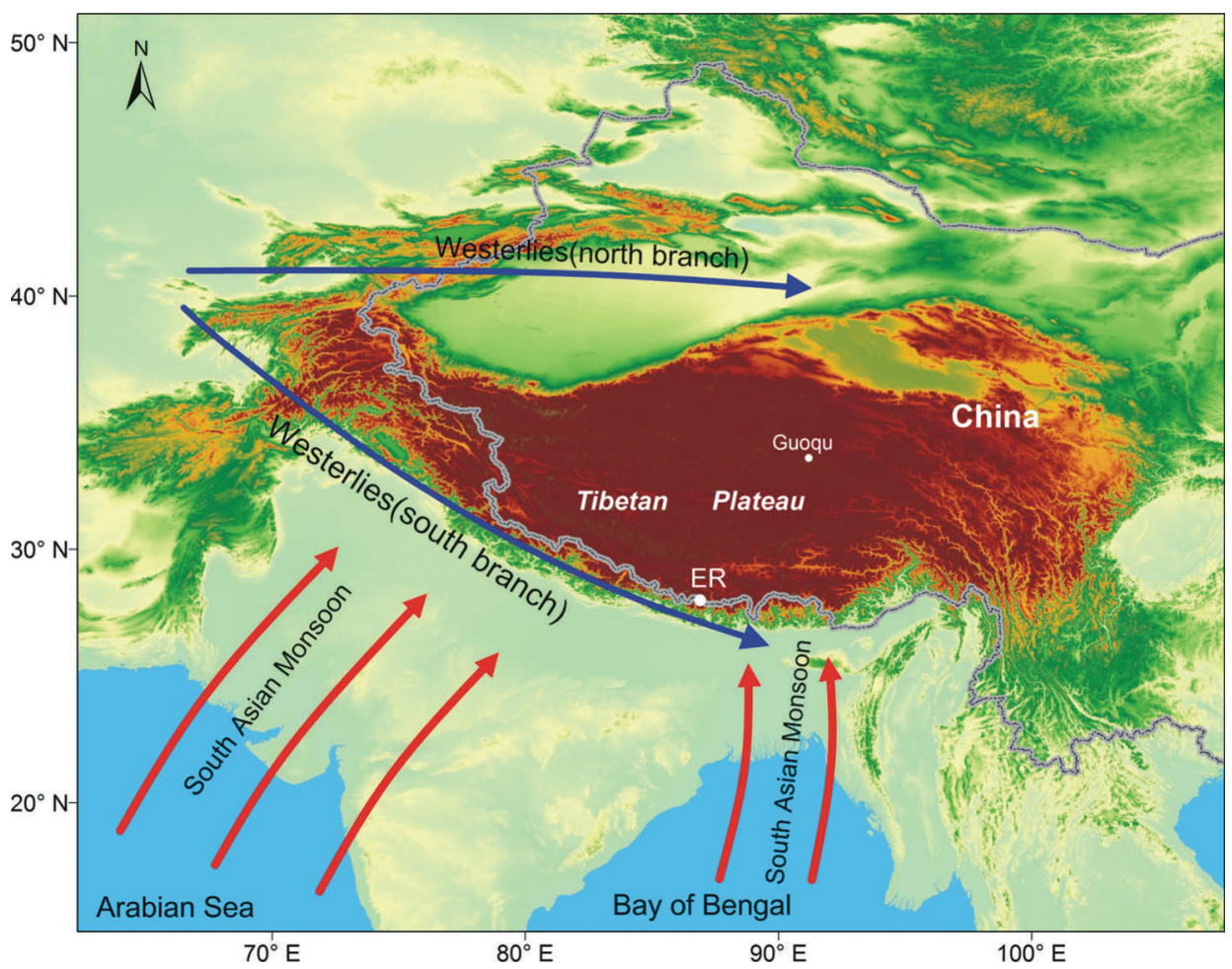

Fig. 1. Location map of east Rongbuk (ER) glacier and atmospheric circulation over the southern Tibetan Plateau (TP). White dots locate ER and Guoqu glaciers. Arrows indicate the general trajectories of the winter westerlies and the summer south Asian monsoon.

Pacific Decadal Oscillation (PDO), so the APO is inversely related to the PDO (Zhou and others, 2009). Zhao and others (2007) reported that the summer APO index may be related to an extratropical zonal vertical circulation between the Asian continent and the north Pacific. Elevated heating by the TP causes the mid-latitude zonal circulation to be upward in Asia and downward in the Pacific, and causes the temperature changes in these regions to be out of phase (Zhao and others, 2007). Thus the APO is closely related to the atmospheric circulation over the TP (Zhao and others, 2008), likely influencing the chemical record of ice cores recovered from the glaciers in this region. In this study, we test whether the APO is indeed represented by the records of major ions in the ER ice core over the past millennium.

\section{DATA AND METHODS}

In 2002, a $108.83 \mathrm{~m}$ ice core was drilled from the col of ER glacier $\left(28^{\circ} 01^{\prime} \mathrm{N}, 86^{\circ} 58^{\prime} \mathrm{E} ; 6518 \mathrm{~m}\right.$ a.s.l.) on the northeast slope of Qomolangma (Mount Everest), central Himalaya. The ice core was maintained at less than $-5^{\circ} \mathrm{C}$ until it reached the laboratory. After decontamination, it was melted and analyzed for several indexes. The concentration of major soluble ions was analyzed by ion chromatography. The ice was dated to AD 1534 at a depth of $98 \mathrm{~m}$ based on seasonal variations in $\delta \mathrm{D}$ and soluble ions, and below $98 \mathrm{~m}$ it was dated by a flow model (Kaspari and others, 2007, 2008). The dating error is \pm 0 years at $A D 1963$ and \pm 5 years at AD 1534 ( $\mathrm{Xu}$ and others, 2010). More details of this ice core are provided by Hou and others (2004), Kaspari and others $(2007,2008)$ and Xu and others (2010). The ice-core base is dated at 1650 years BP applying a simple flow model (Hou and others, 2004); in this study the part of the core spanning the period AD 1003-2002 was used. Figure 2 shows the major-ion concentrations along different depths and the corresponding time series over the past 1000 years.

The recent (1948-2001) APO index reconstructed from US National Centers for Environmental Prediction (NCEP)/US National Center for Atmospheric Research (NCAR) reanalysis data is useful for the study of APO. Zhou and others (2009) analyzed the relationship between the recent APO index and the instrumental summer temperature of Beijing and the PDO index (calculated from instrumental data), and established a regression equation between the recent summer $\mathrm{APO}$ index, Beijing's summer temperature and the PDO index. Using this equation, the summer APO index was extended back to AD 993 via a long time series of Beijing's summer temperature (inferred from a stalagmite record) and a reconstructed time series of the PDO index (http://jisao.washington.edu/pdo/ PDO.latest; Zhou and others, 2009). Analysis shows that the APO index is reliable (Zhou and others, 2009). Below, the reconstructed 993 year time series of the summer APO index (covering the period AD 993-1985) is employed to investigate the correlation between summer APO and the major ions in the past millennium. In view of the dating error, all correlation analysis was conducted after a 5 year running mean smoothing filter was applied to the ionic concentration records and both oscillation indices.

Empirical orthogonal function (EOF) analysis allows robust assessment of the relationships between multiple variables, and EOF decomposition provides objective representations of multivariate data through the analysis of the covariance structure of its variates (Kang and others, 2002). EOF analysis of the major ions of the ice core reveals their common variance and the relationships between major ions, and also yields new time series representing their relationships (Meeker and others, 1995; Kang and others, 2002; Meeker and Mayewski, 2002). EOF analysis was therefore conducted on major ions of the ER ice core. 

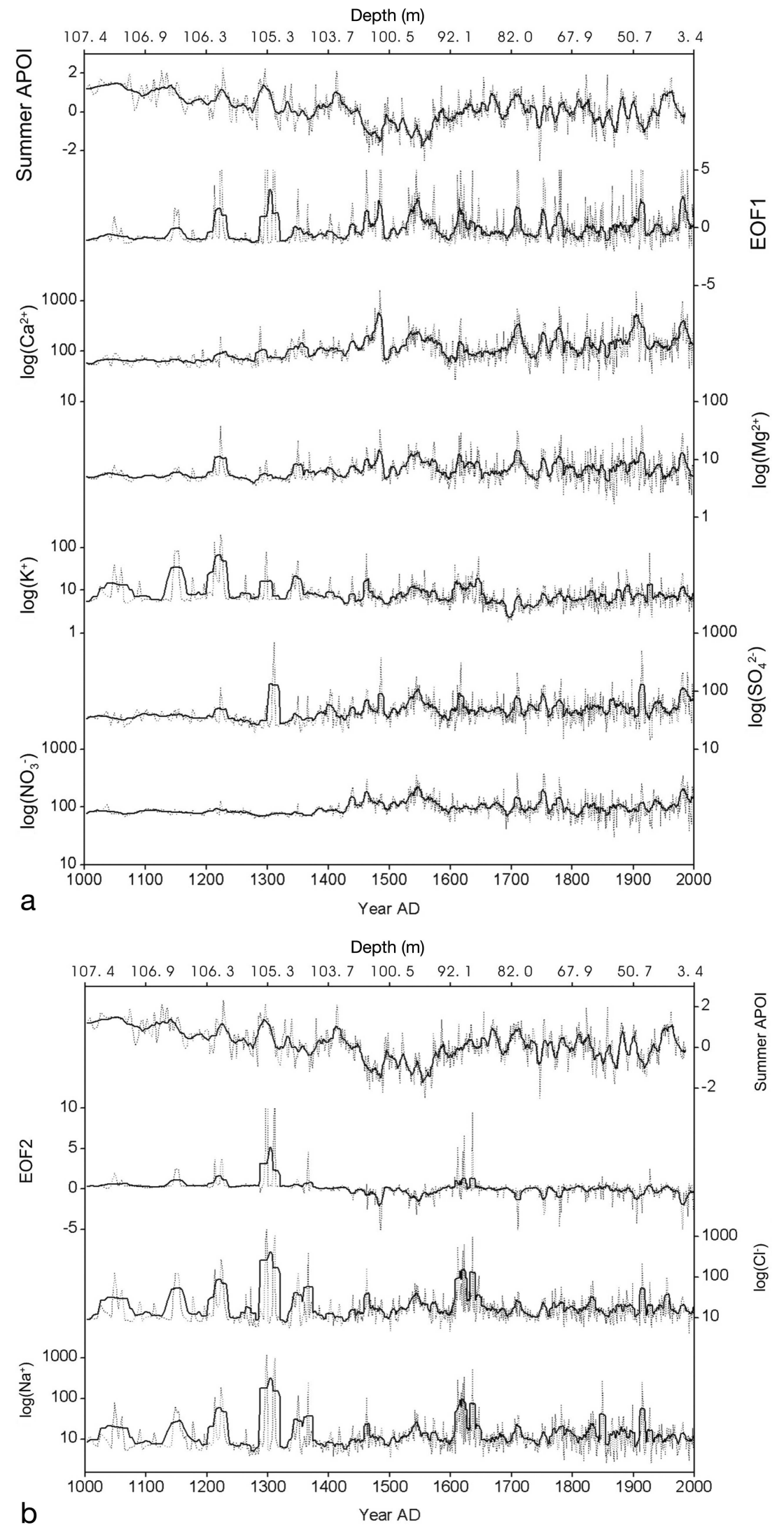

Fig. 2. (a) Time series of EOF1, crustal major ions and summer APO index; (b) time series of EOF2, marine major ions and summer APO index (APOI). Each solid line is the smoothed time series of the thin line, calculated using a 9 year running mean.

\section{RESULTS AND DISCUSSIONS}

\subsection{EOF analysis of major-ion time series}

EOF analysis of the major ions reveals the common variance of these ions over the past millennium (Table 1). EOF1 accounts for $43.8 \%$ of the total variance in the major-ion time series, $\mathrm{Mg}^{2+}, \mathrm{Ca}^{2+}, \mathrm{NO}_{3}{ }^{-}$and $\mathrm{SO}_{4}{ }^{2-}$ are strongly loaded on EOF1, and EOF1 explains $81.0 \%, 63.9 \%, 64.5 \%$ and $81.4 \%$ of changes in $\mathrm{Mg}^{2+}, \mathrm{Ca}^{2+}, \mathrm{NO}_{3}{ }^{-}$and $\mathrm{SO}_{4}{ }^{2-}$ over the past millennium, respectively. Figure 2 shows the EOF time series 
Table 1. Results from EOF analysis of major-ion time series of the ER ice core over the past 1000 years

\begin{tabular}{lcc} 
Ion & $\begin{array}{c}\text { EOF1 } \\
\%\end{array}$ & $\begin{array}{c}\text { EOF2 } \\
\%\end{array}$ \\
\hline $\mathrm{Na}^{+}$ & 62.1 & 74.5 \\
$\mathrm{~K}^{+}$ & 44.3 & 31.7 \\
$\mathrm{Mg}^{2+}$ & 81.0 & -41.0 \\
$\mathrm{Ca}^{2+}$ & 63.9 & -53.2 \\
$\mathrm{Cl}^{-}$ & 58.2 & 77.1 \\
$\mathrm{NO}_{3}{ }^{-}$ & 64.5 & -49.6 \\
$\mathrm{SO}_{4}{ }^{2-}$ & 81.4 & -7.3 \\
$\mathrm{Total}^{(\%)}$ & 43.8 & 27.9 \\
\hline
\end{tabular}

and major ions over the past millennium. The high common variance suggests a common source for these ions, which are possibly derived from mineral aerosol of the central Asia arid zone and controlled by the continental air mass (Wake and others, 1990, 1993, 1994; Kang and others, 2002; Kaspari and others, 2007). EOF1 time series can therefore be used to represent the activities of continental air masses (Kang and others, 2002; Kaspari and others, 2007). EOF2 accounts for $74.5 \%$ and $77.1 \%$ of total $\mathrm{Na}^{+}$and $\mathrm{Cl}^{-}$, respectively. $\mathrm{Na}^{+}$and $\mathrm{Cl}^{-}$, much of which are transported inland during the monsoon season, are associated with marine air masses from the Bay of Bengal and the Arabian Sea (Shrestha and others, 2002; Kaspari and others, 2007). Therefore, the EOF2 time series can be taken as proxies of the activity of the south Asian monsoon (Kaspari and others, 2007).

\subsection{Recent relationships between ion record and temperature and $\mathrm{APO}$}

NCEP/NCAR reanalysis results provide the available global climate data since 1948. In order to investigate the recent relationship between the record of major ions and climatic factors, we compared EOF time series of major ions and climatic data from the NCEP/NCAR reanalysis. The uppertroposphere (200-500 hPa) temperatures (UTT) of the highest and lowest years of the two EOF time series were compared over the period of overlap, 1948-2001. Furthermore, repeating the work of Kang and others (2002) and Kaspari and others (2007), we investigated the surface pressure anomalies of the highest and lowest years of two EOF time series. Because of the inverse relationship between temperature and surface pressure, the values of pressure anomaly are not presented here, but the results of the pressure anomaly of the highest and lowest years of two EOF time series are the same as those obtained by Kang and others (2002) and Kaspari and others (2007).

The results show that, in summer, UTT is anomalously low (high) over Mongolia in years with high (low) EOF1 (Fig. 3a and b), and surface pressure is anomalously high (low) over Mongolia in years with high (low) EOF1. In contrast, higher EOF2 is associated with anomalously high UTT and anomalously low surface pressure over Mongolia (Fig. 3c), and lower EOF2 is associated with anomalously low UTT and anomalously high surface pressure over Mongolia (Fig. 3d). In winter, EOF1 is also inversely related to the UTT anomaly and positively related to surface pressure over Mongolia (Fig. 3e and $\mathrm{f}$ ).

Because the APO phenomenon is observed in tropospheric eddy temperature (a difference bertween air temperature and its zonal mean) (Zhao and others, 2007), the APO index can be regarded as a proxy of the difference in air temperature between Asia and the north Pacific. Additional investigation of the EOF time series and tropospheric eddy temperature was conducted. The results show that in the years of high (low) EOF1, the tropospheric eddy temperature over Mongolia is below (above) average and the tropospheric eddy temperature over the northeast Pacific is above (below) average (Fig. 4a and b). In contrast, in the years of high EOF2, the tropospheric eddy temperature over Mongolia is above (below) average, and the tropospheric eddy temperature over the northeast Pacific is below (above) average (Fig. 4c and d). This suggests that periods showing high (low) concentrations of crustal major ions correspond to times with a weaker (stronger) summer APO, and periods showing high concentrations of marine major ions correspond to times with a stronger (weaker) summer APO.

The thermal gradient between land and sea induces pressure difference which drives atmospheric circulation. Our interpretation of the results so far is that, in the summer, the stronger APO (corresponding with higher UTT and lower pressure over Mongolia) increases this gradient and causes the south Asian monsoon to shift north, weakening the control of the continental air mass over the southern TP. The outcome is higher concentration of marine ions and lower concentration of crustal ions reaching the TP (Kang and others, 2002; Kaspari and others, 2007).

\subsection{Relationship between ion record and reconstructed summer APO index over the past 1000 years}

The 993 year time series of the summer APO index (explained in Section 2) also exhibits long-term variations (Fig. 2). Comparing it with the ion records, we found a weak positive correlation between EOF2 and summer APO index $(r=0.368, p<0.01, n=727)$ and a weak negative correlation between EOF1 and summer APO index $(r=-0.211$, $p<0.01, n=727)$.

However, on the century timescale, the correlation coefficients between major ions and summer APO index in different periods vary temporally (Fig. 2). During the period AD 1000-1440, the summer APO index is above average but the concentrations of crustal ions did not have notably below average values, and the marine ions did not have notably above average values. The correlation coefficient between the summer APO index and EOF1, and the correlation coefficient between this index and EOF2, are both positive in the period AD 1000-1323, which coincides with the Medieval Warm Period (MWP) (Fig. 5). During the MWP, a constant drought has been reported in related areas, including north Africa (Verschuren and others, 2000), India and southeast Asia (Cook and others, 2010), central Asia (Chen and others, 2006) and Europe (Helama and others, 2009). The drought in the source region of crustal ions provides more aerosols to the southern TP. Meanwhile, the intensive source of the ions masked the circulation information of the APO. We therefore infer that the positive association between the summer APO index and both EOFs during the MWP is caused by drought conditions in the ion source regions. Zhao and others (2012) also pointed out that an anomalously high APO index is consistent with reduced precipitation over the arid and semi-arid regions of north Africa, the Middle East and west Asia, which intensified the drought in this region. Higher ion concentrations when the 


\section{a. high EOF1 summer UTT anomaly}

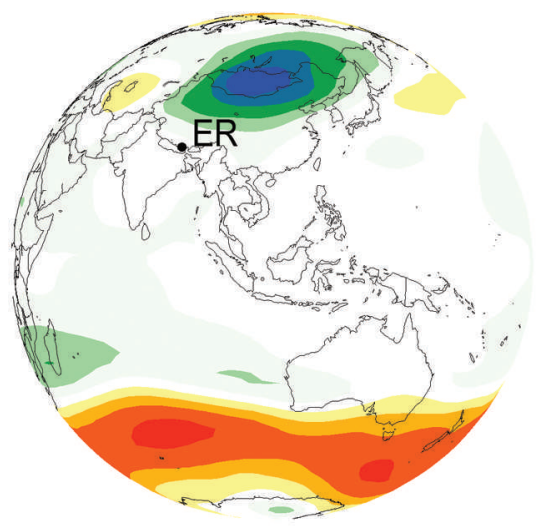

c. high EOF2 summer UTT anomaly

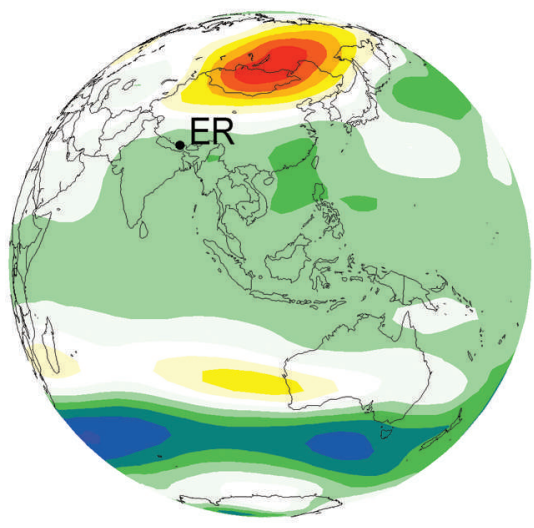

e.high EOF1 winter UTT anomaly

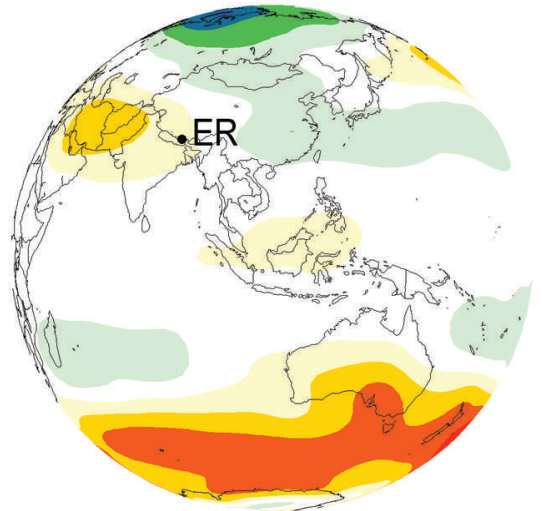

\section{b. low EOF1 summer UTT anomaly}
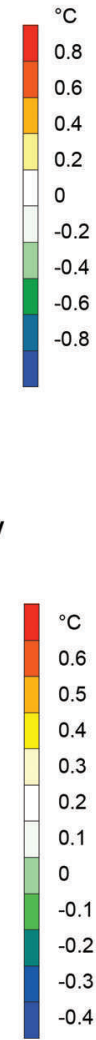

\section{d. low EOF2 summer UTT anomaly}

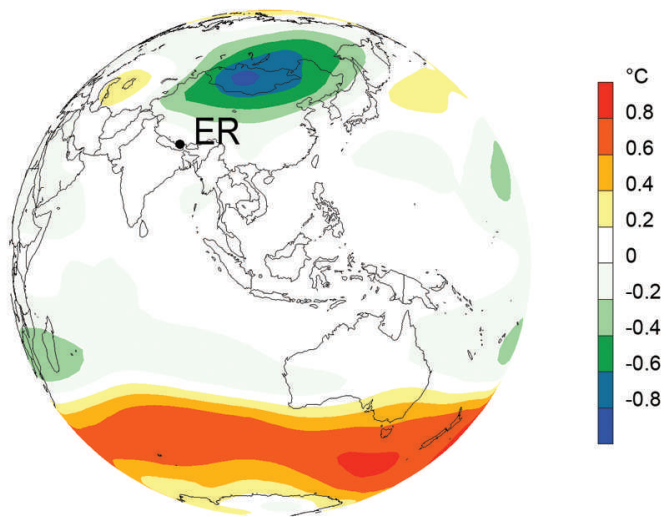

f. low EOF1 winter UTT anomaly

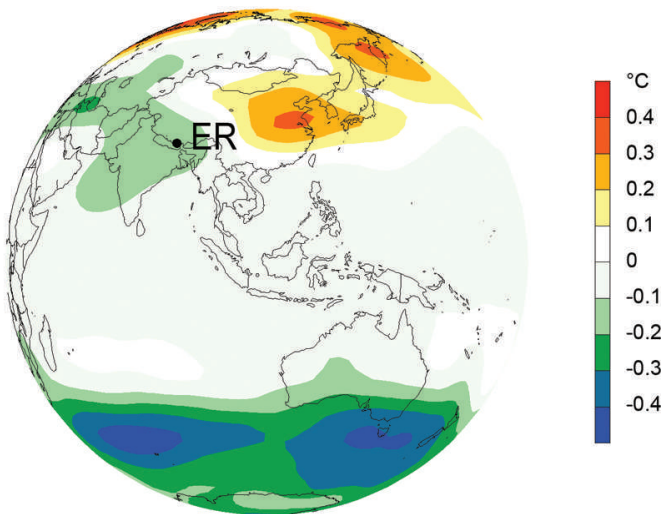

Fig. 3. Upper-troposphere (500-200 hPa) temperature (UTT) anomalies corresponding to different phases of the EOF1 and EOF2 time series. (a, b) Summer (June-September) mean UTT anomaly for (a) high (selected according to the value $\geq$ (mean value $+0.5 \delta)$ ) and (b) low EOF1 years (selected according to the value $\leq($ mean value $-0.5 \delta)$ ); (c, d) summer mean UTT anomaly for (c) high and (d) low EOF2 years; and $(\mathrm{e}, \mathrm{f})$ winter (December-February) mean UTT anomaly for (e) high and (f) low EOF1 years.

APO index was high, during AD 1000-1323, likely imply a dry climate during this period.

From AD 1440 to 1900, the summer APO index was generally lower, fluctuating around zero (Fig. 2). Zhou and others (2009) found that the monsoon circulation during this period was weaker. Over the period AD 1323-1900, the correlation coefficients of summer APO index and EOF time series fluctuate between -1 and 1 (Fig. 5), indicating the unstable relationships between $\mathrm{APO}$ and ion record over the southern TP. These likely reflect the complexity of factors that impact ion transport over the southern TP during AD 1323-1900.
After AD 1900, the correlation between EOF1 and summer APO index is negative and the correlation between EOF2 and summer APO index is positive (Fig. 5). As mentioned above, the higher APO strengthened the south Asian monsoon and weakened the control of continental air mass over the southern TP, hence it influences ion transport over the southern TP. This suggests that after AD 1900 the major-ion records mainly reflect the circulation information.

Both marine aerosols transported inland by the south Asian monsoon and dust derived from the vast arid and semi-arid regions of central Asia play major roles in the ion record of glaciers in the southern TP (Wake and others, 
a. High EOFl eddy temperature anomaly

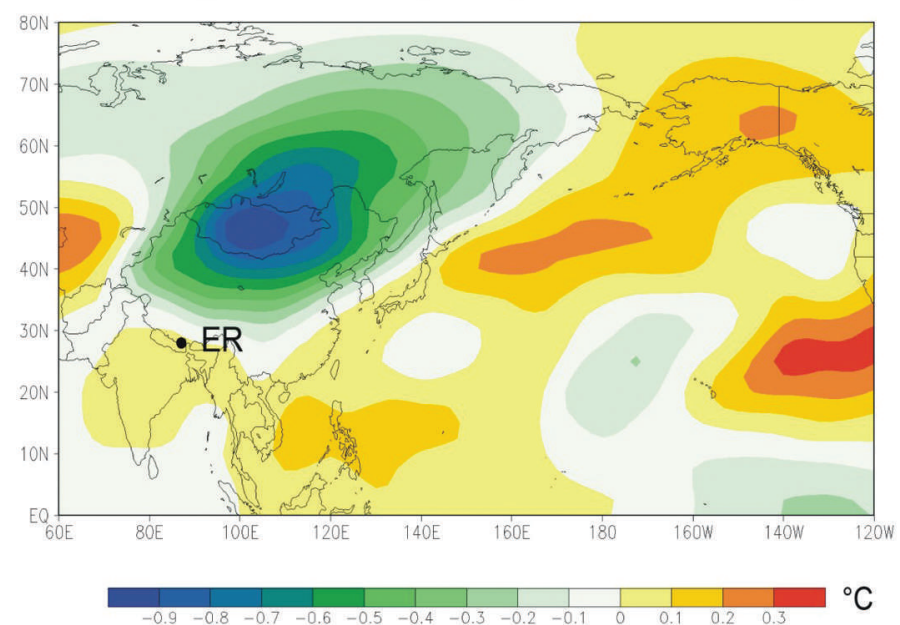

c. High EOF2 eddy temperature anomaly

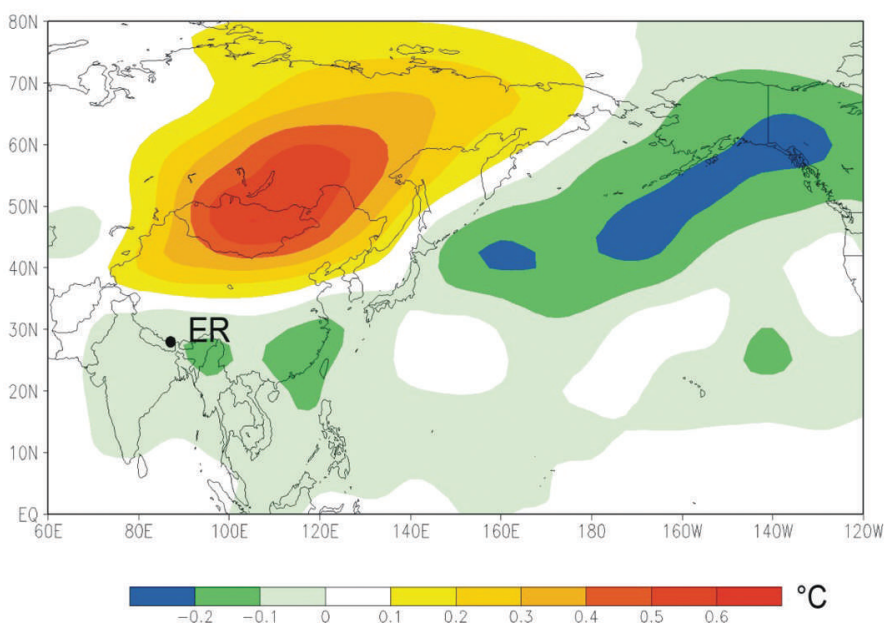

\section{b. LOW EOF1 eddy temperature anomaly}

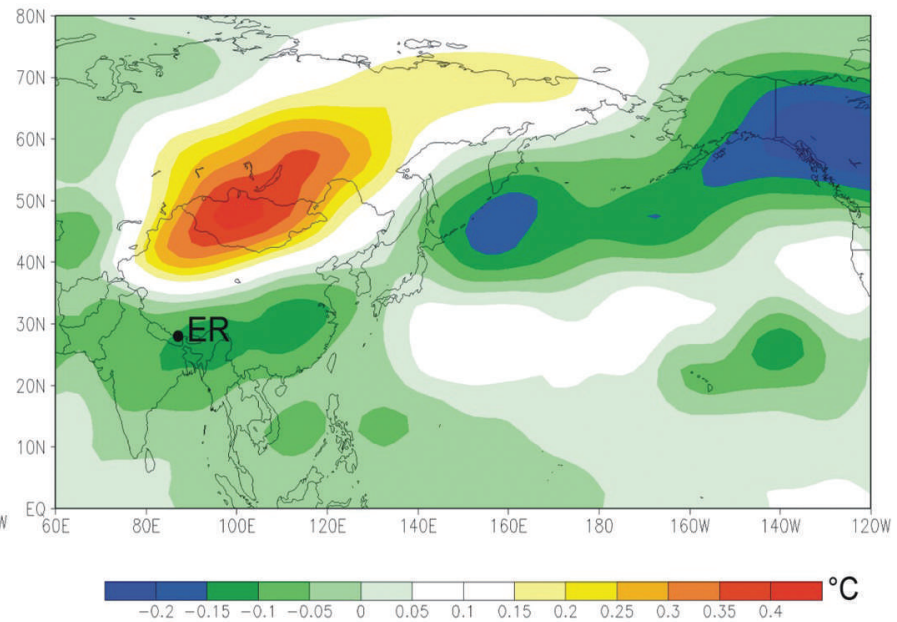

d. Low EOF2 eddy temperature anomaly

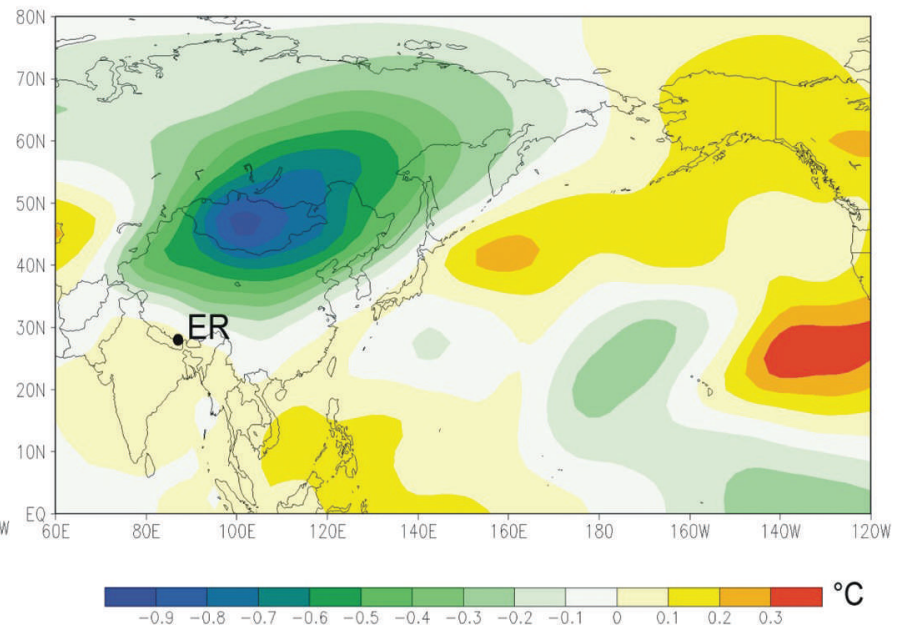

Fig. 4. Eddy temperature anomalies corresponding to different phases of the EOF1 and EOF2 time series. (a, b) Summer mean eddy temperature anomaly for (a) high (selected according the value $\geq$ (mean value $+0.5 \delta)$ ) and (b) low EOF1years (selected according the value $\leq($ mean value $-0.5 \delta)$ ). (c, d) Summer mean eddy temperature for (c) high and (d) low EOF2 years. Here we used the eddy air temperature $\left(T^{\prime}\right)$ as defined by Zhao and others (2007) $\left(T^{\prime}=T-\bar{T}\right)$. $T$ is the air temperature and $T^{\prime}$ is the zonal mean of $T$. The vertically averaged (500-200 mbar) $T^{\prime}$ is used to represent the upper-tropospheric eddy temperature.

1990, 1993, 1994). The south Asian monsoon, zonal wind and activities of Asian dust could impact the ion transport over the southern TP (Wake and others, 1993; Kang and others, 2000, 2002, 2004, 2010; Kaspari and others, 2007, 2009; Liu and others, 2010), and the drought in central and south Asia always contributes a sudden increase of $\mathrm{Cl}^{-}$and $\mathrm{Na}^{+}$which could mask the marine $\mathrm{Cl}^{-}$and $\mathrm{Na}^{+}$(Wake and others, 1993; Grigholm and others, 2009). Therefore the regional atmospheric circulation and the climatic condition of the ion source regions are both factors that could impact ion transport over the southern TP. On the millennial scale, either factor may dominate at different times. Therefore, the correlations between the APO index and the ion record are very weak over the past millennium.

\subsection{Ion record and PDO}

Owing to seesaw teleconnection of the air temperature over the north Pacific and Asia, PDO is inversely correlated with $\mathrm{APO}$, and the abnormal warmer climate of the northeast Pacific region is accompanied by the cooler climate of the Asian continent and vice versa (Zhao and others, 2007;
Zhou and others, 2009). Here we examine the relationship between the record of major ions and the PDO index by studying the correlations between the time series of the EOFs and those of the PDO index (http://jisao.washington.edu/ pdo/PDO.latest, 1900-2000). A previous study has pointed out that there is a teleconnection between the PDO and atmospheric crustal aerosols on the central TP (Grigholm and others, 2009). Our results in Figure 6 show that EOF1 is significantly positively correlated with the annual PDO index $(n=103, r=0.362, p<0.01)$, meaning that when the sea surface temperature is higher over the northeast Pacific, more crustal ions are transported to the southern TP, whereas EOF2 is significantly negatively correlated with the annual PDO index $(n=103, r=-0.409, p<0.01)$, meaning that when the sea surface temperature over the northeast Pacific is low, more marine ions are transported to the southern TP. Additional EOF analysis on EOF time series and the annual PDO index shows that EOF1 and annual PDO index share the $58 \%$ common variations (positive correlation), and EOF2 and the annual PDO index share the $60 \%$ common variations (negative correlation). The high annual PDO 


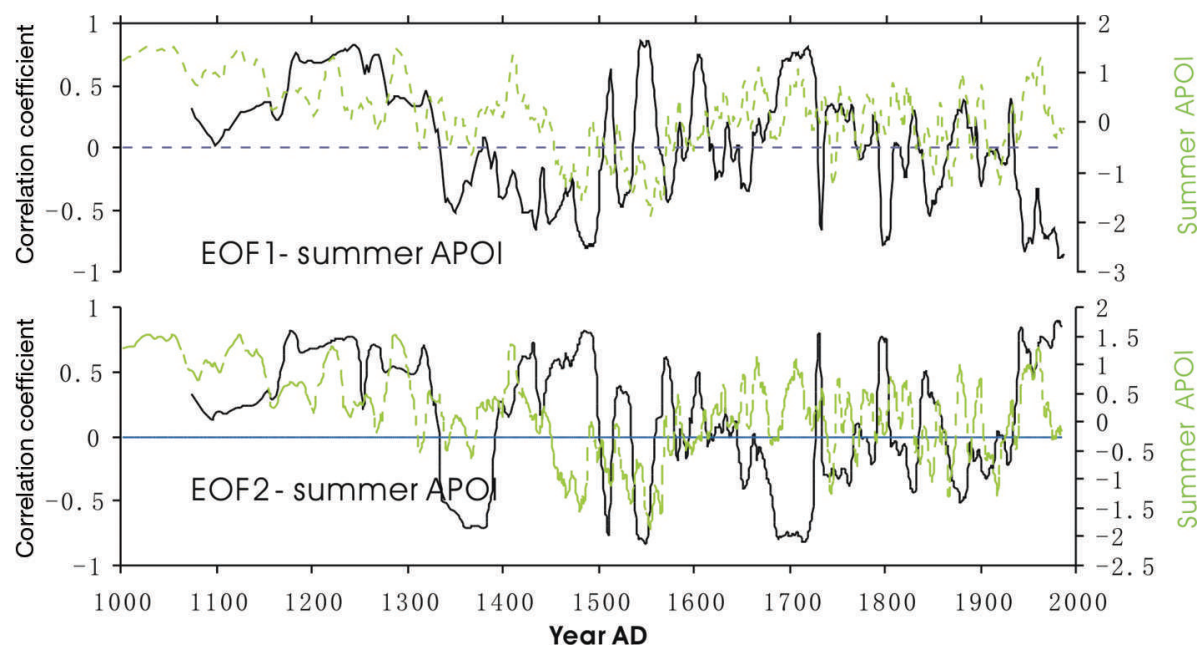

Fig. 5. The 30 year running correlation between the EOF time series and the 993 year time series of the summer APO index (APOI); the latter is reconstructed from Beijing's summer temperature recorded by a stalagmite and the PDO index (Zhou and others, 2009). The black solid line is the correlation coefficient between EOF time series and summer APO index; the green dashed line is summer APO index.

index is related to low APO index (lower UTT and higher surface pressure over Mongolia). When the PDO (APO) index is higher (lower), the air temperature over Eurasia is lower, indicating a stronger continental air mass and a weaker monsoon air mass over the southern TP. Accordingly, the relation between annual PDO index and ion concentration over the southern TP reflects the PDO's impact on atmospheric circulation over the southern TP since AD 1900.

By studying the ion record retrieved from an ice core from Guoqu glacier on the northern side of Geladaindong mountain in the central TP, Grigholm and others (2009) showed that crustal ions are negatively correlated with the PDO index. This observation can be attributed to the fact that negative PDO values correspond to lower precipitation at Geladaindong. The drier condition at Geladaindong due to lower precipitation may provide a favorable environment for a higher burden of soluble dust in the atmosphere, leading to higher concentrations of ions in the Guoqu ice

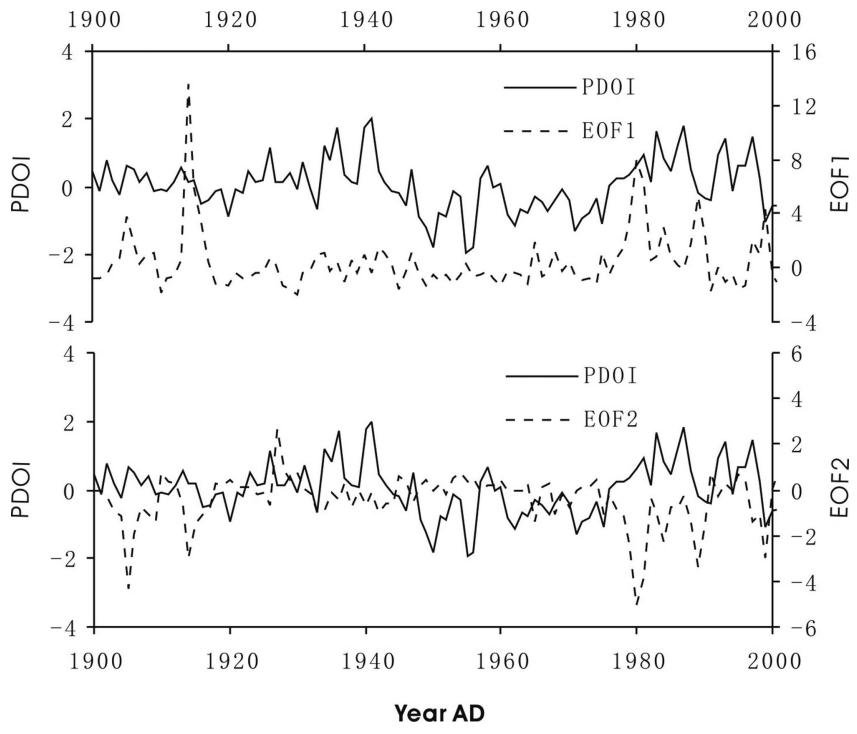

Fig. 6. Time series of the annual values of EOF1, EOF2 and the PDO index (PDOI). core. The negative correlation between the Guoqu icecore crustal ions and the PDO index is opposite to the positive correlation between the PDO index and the ER icecore crustal ions, which may suggest the different mechanisms of the PDO's impact on ion transport to the central and southern TP. The influence of PDO on the Guoqu ice-core crustal ions may emphasize its impact on ion sources (drier or wetter environment), but its influence on ER ice-core crustal ions emphasizes its impact on ion transport (atmospheric circulation strength) since AD 1900.

\section{CONCLUSIONS}

EOF analysis of the major ions in the ER ice core reveals the relationships among major ions and their common variation. EOF1 represents the common variance of the major crustal ions, and EOF2 represents the fluctuations of marine ions over the southern TP. UTT and surface pressure over the Mongolia region are closely related to ion transport over the southern TP. Periods of increased marine ions and decreased crustal ions correspond to times when higher UTT occurred over Mongolia. Investigations of the most recent 54 years (1948-2001) of the EOF time series and tropospheric eddy temperature indicate that the summer higher APO strengthened the south Asian monsoon and lower summer APO strengthened the control of continental air mass over the southern TP. This suggests that the record of major ions of the ER ice core can document the APO signals.

The ion concentrations measured in the southern TP ice core are influenced by both the regional atmospheric circulation and the climatic conditions of the ion source regions. During the last millennium, these factors varied over time. Because either factor may dominate at a given time, the correlations between the summer APO index and the EOF time series are weak.

Finally, an inverse relation between annual PDO index and concentration of crustal ions over Geladaindong and a positive relation between $\mathrm{PDO}$ index and crustal ion concentration on Qomolangma suggest two effects of the PDO: (1) it can influence the source of ions reaching the central TP, and (2) it can influence the transport of major ions (circulation) to the southern TP. 


\section{ACKNOWLEDGEMENTS}

Thanks are due to many scientists, technicians, graduates and porters for their hard work in the field, and to Zhao Ping for providing the APO index. This work was supported in China by the Chinese Academy of Sciences (XDB03030101-4), the National Basic Research Program of China (2010CB951401), the Natural Science Foundation of China (41330526, 41171052, 41321062 and 40825017), the Ministry of Education (20110091110025) and the Priority Academic Program Development of Jiangsu Higher Education Institutions. We thank our editor, Felix $\mathrm{Ng}$, and an anonymous reviewer for extensive suggestions on the science and the written English of the manuscript.

\section{REFERENCES}

Chen F, Huang X, Zhang J, Holmes JA and Chen J (2006) Humid Little Ice Age in arid central Asia documented by Bosten Lake, Xinjiang, China. Sci. China D, 49(12), 1280-1290 (doi: 10.1007/s11430-006-2027-4)

Cook ER, Anchukaitis KJ, Buckley BM, D'Arrigo RD, Jacoby GC and Wright WE (2010) Asian monsoon failure and megadrought during the last Millennium. Science, 328(5977), 486-489 (doi: 10.1126/science.1185188)

Grigholm B and 6 others (2009) Atmospheric soluble dust records from a Tibetan ice core: possible climate proxies and teleconnection with the Pacific Decadal Oscillation. J. Geophys. Res., 114(D20), D20118 (doi: 10.1029/2008JD011242)

Helama S, Meriläinen J and Tuomenvirta H (2009) Multicentennial megadrought in northern Europe coincided with a global El NiñoSouthern Oscillation drought pattern during the Medieval Climate Anomaly. Geology, 37(2), 175-178 (doi: 10.1130/G25329A.1)

Hou S, Qin D, Zhang D, Kang S, Mayewski PA and Wake CP (2003) A 154 a high-resolution ammonium record from the Rongbuk Glacier, north slope of Mt. Qomolangma (Everest), Tibet-Himal region. Atmos. Environ., 37(5), 721-729 (doi: 10.1016/S13522310(02)00582-4)

Hou S and 7 others (2004) Correspondence. Age of Himalayan bottom ice cores. J. Glaciol., 50(170), 467-468 (doi: 10.3189/ 172756504781829981)

Kang S, Wake CP, Qin D, Mayewski PA and Yao T (2000) Monsoon and dust signals recorded in Dasuopu Glacier, Tibetan Plateau. J. Glaciol., 46(153), 222-226 (doi: 10.3189/ 172756500781832864)

Kang S and 7 others (2002) Glaciochemical records from a Mt. Everest ice core: relationship to atmospheric circulation over Asia. Atmos. Environ., 36(21), 3351-3361 (doi: 10.1016/ S1352-2310(02)00325-4)

Kang SC, Mayewski PA, Qin DH, Sneed SA, Ren JW and Zhang DQ (2004) Seasonal differences in snow chemistry from the vicinity of Mt. Everest, central Himalayas. Atmos. Environ., 38(18), 2819-2829 (doi: 10.1016/j.atmosenv.2004.02.043)

Kang S and 7 others (2010) Variability of atmospheric dust loading over the central Tibetan Plateau based on ice core glaciochemistry. Atmos. Environ., 44(25), 2980-2989 (doi: 10.1016/ j.atmosenv.2010.05.014)

Kaspari S and 11 others (2007) Reduction in northward incursions of the South Asian monsoon since $\sim 1400$ AD inferred from a Mt. Everest ice core. Geophys. Res. Lett., 34(16), L16701 (doi: 10.1029/2007GL030440)

Kaspari S, Hooke RLeB, Mayewski PA, Kang S, Hou S and Qin D (2008) Snow accumulation rate on Qomolangma (Mount Everest), Himalaya: synchroneity with sites across the Tibetan Plateau on 50-100 year timescales. J. Glaciol., 54(185), 343-352 (doi: 10.3189/002214308784886126)

Kaspari S and 7 others (2009) A high-resolution record of atmospheric dust composition and variability since A.D. 1650 from a Mount Everest ice core. J. Climate, 22(14), 3910-3925 (doi: 10.1175/2009JCLI2518.1)

Liu Y, Geng Z and Hou S (2010) Spatial and seasonal variation of major ions in Himalayan snow and ice: a source consideration. J. Asian Earth Sci., 37(2), 195-205 (doi: 10.1016/j.jseaes.2009. 08.006)

Mayewski PA, Lyons WB, Ahmad N, Smith G and Pourchet M (1984) Interpretation of the chemical and physical time-series retrieved from Sentik Glacier, Ladakh Himalaya, India. J. Glaciol., 30(104), 66-76

Meeker LD and Mayewski PA (2002) A 1400-year highresolution record of atmospheric circulation over the North Atlantic and Asia. Holocene, 12(3), 257-266 (doi: 10.1191/ 0959683602hl542ft)

Meeker LD, Mayewski PA and Bloomfield P (1995) A new approach to glaciochemical time series analysis. In Delmas RJ ed. Ice core studies of global biogeochemical cycles. (NATO ASI Series I: Global Environmental Change 30) Springer, Berlin, 383-400

Shrestha AB, Wake CP, Dibb JE and Whitlow SI (2002) Aerosol and precipitation chemistry at a remote Himalayan site in Nepal. Aerosol Sci. Technol., 36(4), 441-456 (doi: 10.1080/ $027868202753571269)$

Thompson LG and 9 others (1989) Holocene-Late Pleistocene climatic ice core records from Qinghai-Tibetan Plateau. Science, 246(4929), 474-477 (doi: 10.1126/science.246.4929.474)

Thompson LG and 9 others (1997) Tropical climate instability: the last glacial cycle from a Qinghai-Tibetan ice core. Science, 276(5320), 1821-1825 (doi: 10.1126/science.276.5320.1821)

Thompson LG, Yao T, Mosley-Thompson E, Davis ME, Henderson KA and Lin P (2000) A high-resolution millennial record of the south Asian monsoon from Himalayan ice cores. Science, 289(5486), 1916-1919 (doi: 10.1126/science.289.5486.1916)

Verschuren D, Laird KR and Cumming BF (2000) Rainfall and drought in equatorial east Africa during the past 1,100 years. Nature, 403(6768), 410-414 (doi: 10.1038/35000179)

Wake CP, Mayewski PA and Spencer MJ (1990) A review of central Asian glaciochemical data. Ann. Glaciol., 14, 301-306

Wake CP, Mayewski PA, Xie Z, Wang P and Li Z (1993) Regional distribution of monsoon and desert dust signals recorded in Asian glaciers. Geophys. Res. Lett., 20(14), 1411-1414 (doi: 10.1029/93GL01682)

Wake CP, Dibb JE, Mayewski PA, Li Z and Xie Z (1994) The chemical composition of aerosols over the eastern Himalayas and Tibetan plateau during low dust periods. Atmos. Environ., 28(4), 695-704 (doi: 10.1016/1352-2310(94)90046-9)

$\mathrm{Xu} \mathrm{J}$ and 10 others (2010) A 108.83-m ice-core record of atmospheric dust deposition at Mt. Qomolangma (Everest), Central Himalaya. Quat. Res., 73(1), 33-38 (doi: 10.1016/ j.yqres.2009.09.005)

Zhao P, Zhu Y and Zhang R (2007) An Asian-Pacific teleconnection in summer tropospheric temperature and associated Asian climate variability. Climate Dyn., 29(2-3), 293-303 (doi: 10.1007/s00382-007-0236-y)

Zhao P, Chen J, Xiao D, Nan S, Zou Y and Zhou B (2008) Summer Asian-Pacific oscillation and its relationship with atmospheric circulation and monsoon rainfall. Acta Meteorol. Sin., 22(4), 455-471

Zhao P, Cao Z and Chen J (2010) A summer teleconnection pattern over the extratropical Northern Hemisphere and associated mechanisms. Climate Dyn., 35(2-3), 5223-5234 (doi: 10.1007/ s00382-009-0699-0)

Zhao P, Wang B and Zhou X (2012) Boreal summer continental monsoon rainfall and hydroclimate anomalies associated with the Asian-Pacific Oscillation. Climate Dyn., 39(5), 1197-1207 (doi: 10.1007/s00382-012-1348-6)

Zhou X, Zhao P and Liu G (2009) Asian-Pacific Oscillation index and variation of East Asian summer monsoon over the past millennium. Chinese Sci. Bull., 54(20), 3768-3771 (doi: 10.1007/s11434-009-0619-z) 